\title{
Changes in Acute Poststreptococcal Glomerulonephritis: An Observation Study at a Single Korean Hospital OverTwo Decades
}

\author{
Sueng-Woo Kuem, M.D. ', \\ Sun-Mi Hur, M.D. ${ }^{1}$, \\ You-Sook Youn, M.D. ${ }^{1,2}$, \\ Jung-Woo Rhim, M.D. 1,2, \\ Jin-Soon Suh, M.D. ${ }^{1}$, \\ Kyung-Yil Lee, M.D. ${ }^{1,2}$ \\ 'Departments of Pediatrics, College \\ of Medicine The Catholic University of \\ Korea, Seoul, Republic of Korea. ${ }^{2}$ Depart- \\ ment of Pediatrics, The Catholic Universi- \\ ty of Korea, Daejeon St. Mary's Hospital, \\ Daejeon, Republic of Korea
}

\author{
Corresponding author: \\ Kyung-Yil Lee, M.D. \\ Department of Pediatrics, The Catholic \\ University of Korea, Daejeon St. Mary's \\ Hospital, 64 Daeheung-ro, Jung-gu, \\ Daejeon 301-723, Republic of Korea \\ Tel: +82-42-220-9540 \\ Fax: +82-42-221-2925 \\ E-mail: leekyungyil@catholic.ac.kr
}

This study has no fund.

Received: 12 August 2015

Revised: 13 October 2015

Accepted: 25 October 2015

\begin{abstract}
This is an open-access article distributed under the terms of the Creative Commons Attribution Non-Commercial License (http:// creativecommons.org/licenses/bync/3.0/) which permits unrestricted non-commercial use, distribution, and reproduction in any medium, provided the original work is properly cited.
\end{abstract}

Purpose: The incidence of acute poststreptococcal glomerulonephritis (APSGN) in Korea has changed. This study aimed to evaluate the epidemiological and clinical changes of APSGN observed in a single Korean institution over two decades.

Methods: We retrospectively analyzed the data of 99 children (0-15 years of age) who were admitted to our institution with APSGN between 1987 and 2013. The patients were selected based on the depression of serum complement 3 ( $C 3,<70$ $\mathrm{mg} / \mathrm{dL}$ ) and elevated titer of antistreptolysin $\mathrm{O}$ (ASO, $>250 \mathrm{lU} / \mathrm{dL}$ ) as evidence of previous streptococcal infection.

Results: In the 99 patients, the mean age was $8.3 \pm 2.7$ years, and the male-tofemale ratio was 2.2:1 (66:30). The annual number of cases fluctuated markedly, and most cases were observed during the late autumn and winter months. However, there have been few cases reported in the past 5 years. Clinical manifestations at presentation, including hypertension and generalized oedema, and the duration of hospitalization were higher and longer in patients admitted during the first half of the study period than during the most recent half-period, suggesting a more severe clinical course in the former group.

Conclusions: APSGN has become a rare disease in Korea with a trend towards a less severe clinical course. This finding suggests that the prevalence of infection-related immune-mediated diseases could change over-time, together with environmental and possibly pathogen-host relationship changes.

Key words: Poststreptococcal glomerulonephritis, Epidemiology, Children

\section{Introduction}

Acute poststreptococcal glomerulonephritis (APSGN) is a representative immune-mediated disease that occurs after a known bacterial infection, such as Group A $\beta$-hemolytic streptococci (GAS). The changing epidemiology of GAS infection has been well documented ${ }^{1,2)}$, and evidence suggests that APSGN, one of the nonsuppurative complications of GAS infection, is becoming a rare disease in developed countries ${ }^{3-5)}$. However, sporadic cases have occurred in developed countries ${ }^{6}$, and the global burden of post-streptococcal disease may remain high in developing countries ${ }^{7}$.

South Korea is one of the rapidly grown developed countries after the Second World War. As observed in other developed countries, the epidemiology of 
infectious diseases and infection-related immune-mediated diseases, including APSGN, has changed along with economic growth in Korea. In this study, we found that recent clinical manifestations of APSGN were less severe than in the past, although there have been few prospective studies concerning this topic. These findings suggest that, in addition to environmental factors such as an improved socioeconomic state and the introduction of antibiotics, other factors may be associated with the changing epidemiology of GAS and other pathogen infections ${ }^{1,2)}$. In addition, although it is understood that the substances produced after GAS infection elicit inflammation in renal tissues, the changing epidemiology of APSGN remains elusive as well as the pathogenesis ${ }^{7,8)}$.

In the present study, we evaluated the epidemiological data of APSGN in our department over two decades and we briefly reviewed reasons for the changing epidemiology of APSGN based on the clinical characteristics of the disease.

\section{Materials and methods}

The study was conducted in a secondary general hospital for the primary care of APSGN patients in Daejeon, Korea. Daejeon is one of the largest cities in South Korea located in the central part of the country. During the study period, the population of the city increased from approximately a million in 1987 to 1.5 million in 2013. Most of the APSGN patients may have been admitted to 4 general hospitals before 1999 and since 2000 to 5 general hospitals including ours. Although the increased population, dispersion of patients to other hospitals and decreasing birth rate in Korea may affect the subjects of this study, there were no remarkable changes in the policy of hospitalization and treatment in our department during the study period.

We retrospectively analyzed the data of 99 children (0-15 years of age) with APSGN who were admitted to The Catholic University of Korea, Daejeon St. Mary's Hospital between January 1987 and December 2013. For this study, we reviewed the medical records of APSGN patients admitted between 1996 and 2013, and used preliminary study data previously prepared for patients admitted between 1987 and 1995. All patients diagnosed with APSGN satisfied the following criteria: acute onset glomerulonephritis with hematuria (with or without proteinuria), reversible depression of serum complement $3(\mathrm{C} 3,<70 \mathrm{mg} / \mathrm{dL})$, and elevated titer of antistreptolysin $\mathrm{O}$ (ASO, $\geq 250 \mathrm{IU} / \mathrm{dL}$ ) as evidence of previous streptococcal infection. Patients not meeting both laboratory criteria were excluded from this series. There were no patients that did not recover from a depressed C3 in follow-up examination. The methods for ASO testing were changed during the study period from semi-quantitative to quantitative, and values of $166-333$ Todd unit $/ \mathrm{mL}$ before 1995 , and $\geq 250 \mathrm{IU} / \mathrm{mL}$ after 1996 were used for patient selection, and median value of semi-quantitative values was used for statistical analysis. Hypertension was defined as a systolic blood pressure of $\geq 95$ percentile of age- and sex-matched healthy Korean children. Microscopic hematuria was defined as $\geq 5$ red blood cells per high-power field. Demographic data and clinical features such as hypertension, generalized oedema, gross hematuria, hospitalization day, and laboratory findings including ASO, C3, hemoglobin, blood urea nitrogen (BUN), and creatinine at admission were assessed. To investigate clinical changes during the study period, we analyzed the data between patients admitted during the early period (1987-1999, $\mathrm{n}=69)$ and patients admitted during the most recent period (2000-2013, n=30).

Written consent for clinical records to be used in future studies was obtained from the parents or guardians of all patients at admission. The study was approved by the Institutional Review Board of the Catholic University of Korea, Daejeon St Mary’s Hospital (DC14RISI9927).

\section{Statistical Analysis}

All calculations were performed with SPSS ver. 14.0 (SPSS Inc., Chicago, IL, USA). Comparisons between groups were performed using the Student's t-test for continuous variables, and the $\chi 2$ test method for categorical variables. A P value of $<0.05$ was considered statistically significant.

\section{Results}

\section{Demographic findings of the patients}

In 99 patients, the mean age was $8.3 \pm 2.7$ years (ranged from 3 to 15 years), and the male-to-female ratio was and 2.3:1 (69:30). The peak age range of presentation was 9 


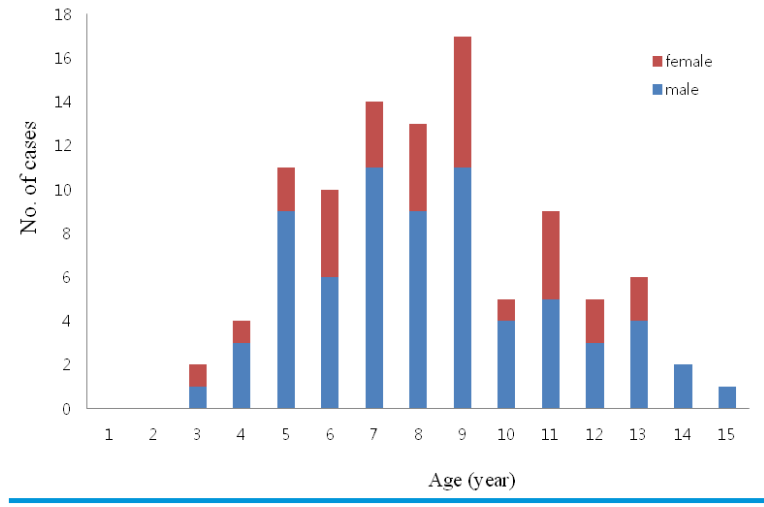

Fig. 1. Age distribution of total patients with acute poststreptococcal glomerulonephritis $(\mathrm{n}=99)$

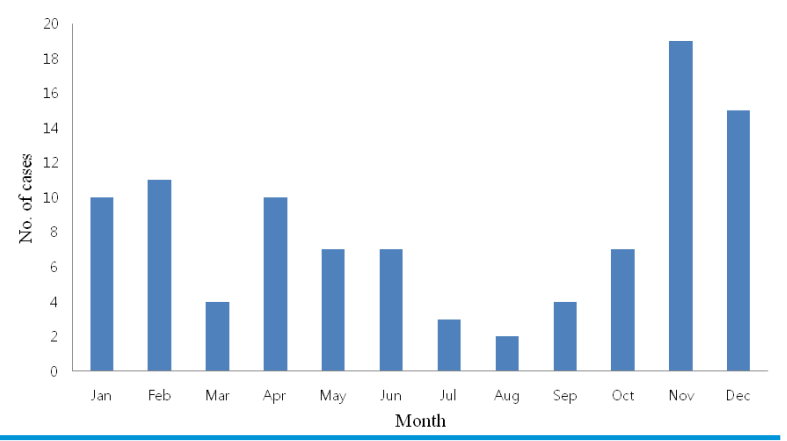

Fig. 3. Monthly cases of total patients with acute poststreptococcal glomerulonephritis

years $(17 / 99,17 \%)$, and most children were $5-11$ years old (79/99, 80\%), also called school-aged children. There were no patients $\leq 2$ years old (Fig. 1).

\section{Annual and monthly cases from patients admitted during 1987-2013}

The annual number of cases during the study period is shown in Fig. 2. The frequency of cases fluctuated markedly over the years, with clustering of patients ( $>5$ patients/year) last noted in 2003 (9 patients). Since 2008, only one case of APSGN has been noted. In terms of seasonal frequency, the highest number of patients was seen in November (19/99, $19.2 \%)$, and more than half the patients were diagnosed between November and February (55/99, 55.6\%). Overall, the majority of cases were observed during winter (Dec. to Feb., 36/99, 36.4\%), followed by autumn (Sept. to Nov., 30/99, 30.3\%), spring (Mar. to May, 21/99, 21.2\%), and summer (12/99, 12.1\%) (Fig. 3).

When we compared the seasonality of the both groups, however, there were some differences: in the 1987-1999 group,

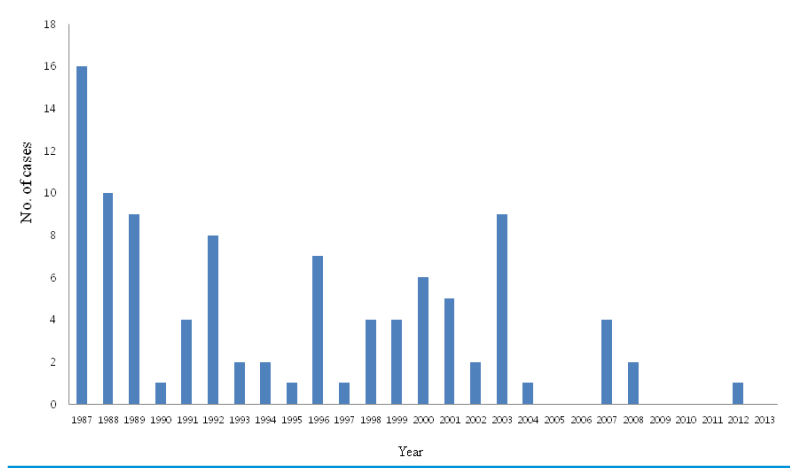

Fig. 2. Annual cases of acute poststreptococcal glomerulonephritis patients from 1987 to 2013

autumn ( 25 cases), winter ( 23 cases), spring (12 cases), and summer ( 9 cases) were noted, whereas in the 2000-2013 group, winter ( 13 cases), spring ( 9 cases), autumn ( 5 cases), and summer ( 3 cases) were noted.

\section{Clinical comparison between the 1987-1999 group and the 2000-2013 group}

The clinical signs of all the patients at presentation were noted as follows: hypertension $(25.3 \%, 25 / 99)$, generalized oedema (57.6\%), and gross hematuria (66.7\%). In this series, no patients had previous skin infections or renal sequelae after APSGN, such as chronic renal disease. All patients had microscopic hematuria (100\%) and 25 patients (25.3\%) had increased BUN levels of $>20 \mathrm{mg} / \mathrm{dL}$ at presentation. On comparison of the data from patients admitted during 1987-1999 with those admitted during 2000-2013, the age of patients was older $(P=0.002)$, the rates of hypertension $(P=0.005)$ or generalized oedema $(P<0.001)$ at presentation and the duration of hospitalization $(P<0.001)$ were significantly higher or longer (Table 1 ). The age distribution showed some differences between the groups and there was a trend that the patients of $\leq 5$ years of age were significant prevalent $(P=0.005)$ and the patients of $10-15$ years of age were less prevalent in the 2000-2013 group compare to the 1987-1999 group (Table 2).

Some detailed clinical data, including disease-onset after initial GAS infection and clinical complications such as nephritic syndrome with acute kidney injury and/or nephrotic syndrome during hospitalization, could not be evaluated because of unavailability of medical records before 1995. However, there were few patients that received renal replacement therapy due to complications of the disease. 
Table 1. Clinical and laboratory findings of the patients admitted during 1987-1999 and 2000-2013

\begin{tabular}{|c|c|c|c|}
\hline Age groups & $\begin{array}{c}1987-1999 \\
(n=69)\end{array}$ & $\begin{array}{c}2000-2013 \\
(n=30)\end{array}$ & P \\
\hline \multicolumn{4}{|l|}{ Clinical characteristics } \\
\hline Age (y) & $8.9 \pm 2.7$ & $7.0 \pm 2.8$ & 0.002 \\
\hline Male:female & $46: 23$ & $23: 7$ & 0.32 \\
\hline Hypertension (n,\%) & $23(33.3)$ & $2(6.7)$ & 0.005 \\
\hline Generalized oedema & $49(71)$ & $8(26.7)$ & $<0.001$ \\
\hline Gross hematuria $(n, \%)$ & $43(62.3)$ & $23(76.7)$ & 0.164 \\
\hline Hospitalization (d) & $14.9 \pm 7.3$ & $8.5 \pm 3.1$ & $<0.001$ \\
\hline \multicolumn{4}{|l|}{ Laboratory findings } \\
\hline Hemoglobin (g/dL) & $11.3 \pm 1.1$ & $10.9 \pm 0.9$ & 0.193 \\
\hline Leukocyte (x103//uL) & $10.5 \pm 4.7$ & $8.7 \pm 2.8$ & 0.063 \\
\hline ASO (IU/L) & $493 \pm 284$ & $1001 \pm 829$ & 0.003 \\
\hline C3 (mg/dL) & $24.3 \pm 18.5$ & $32.6 \pm 19.1$ & 0.052 \\
\hline BUN (mg/dL) & $19.9 \pm 12.7$ & $17.6 \pm 11$ & 0.269 \\
\hline BUN > 20 mg/dL $(n, \%)$ & $20(29)$ & $5(16.7)$ & 0.195 \\
\hline Creatinine (mg/dL) & $0.88 \pm 0.8$ & $0.64 \pm 0.17$ & 0.107 \\
\hline Total protein (g/dL) & $6.6 \pm 0.6$ & $6.4 \pm 0.7$ & 0.209 \\
\hline Albumin (g/dL) & $3.7 \pm 0.5$ & $3.7 \pm 0.5$ & 0.995 \\
\hline
\end{tabular}

ASO, antistreptolysin O; BUN, blood urea nitrogen

Data were obtained at presentation of the patients.

Table 2. Age distribution of the patients admitted during 1987-1999 and 2000-2013

\begin{tabular}{lccc}
\hline Age groups & $\begin{array}{c}1987-1999 \\
(n=69)\end{array}$ & $\begin{array}{c}2000-2013 \\
(n=30)\end{array}$ & $p$ \\
\hline$\leq 5$ years of age $(n, \%)$ & $7(10.1)$ & $10(33.3)$ & 0.005 \\
$6-9$ years of age & $43(62.3)$ & $16(53.3)$ & 0.402 \\
$10-15$ years of age & $19(27.5)$ & $4(13.3)$ & 0.124 \\
\hline
\end{tabular}

Laboratory findings were similar in both groups except for a significantly higher ASO titer and a trend of higher $\mathrm{C} 3$ value in the 2000 - 2013 group (Table 1).

\section{Discussion}

Earlier studies in Korea showed that APSGN might be an endemic disease which occurred every year, mainly during the fall-winter season in the 1960-70 ${ }^{9,10)}$. Along with economic growth in Korea, the incidence of APSGN reduced, and it changed from being an endemic disease to occurring as sporadic outbreaks during the 1980s to early $2000 \mathrm{~s}^{11,12)}$. The studies performed during the mid-1990sto mid-2000s, including ours, at a single institution in different cities showed an intermittent clustering of cases, but outbreak-years were different across the study groups ${ }^{11,12}$.
This finding is unlike nationwide epidemics of viral infection such as influenza and enterovirus infection, and it suggests that outbreaks of bacterial infections depend on the situation of a local community. In addition, we found few cases after 2008, suggesting that APSGN may soon become a "forgotten disease" in Korea, like acute rheumatic fever. There have been few clinical study reports of acute rheumatic fever in the paediatric field since 1999 in the Korean literature ${ }^{13)}$. Similar findings had already been observed in many developed countries including European countries and the United States before the 1980-90s, but this phenomenon may be observed globally in various countries that have different economic state and healthcare environments ${ }^{4-7,14,15)}$. Although the changing epidemiology of GAS infection may be associated with environmental changes, such as improved public hygiene and the wide-use of antibiotics ${ }^{1,2)}$, this study demonstrates that it 
can also occur during a period of steady environmental state in a nation, since there have been no notable changes in the medical or social environment during the past decade in Korea.

Most of APSGN patients recover uneventfully, but some severely affected patients have complications such as acute kidney injury or nephrotic syndrome. Although there were few severely affected patients in this series, we found that the clinical course of the disease seemed to be milder in the 2000-2013 cases compared to the 1987-1999 cases, as assessed by the duration of hospitalization and the presence of hypertension and generalized oedema at presentation. Also, we found that the age distribution was somewhat different between the groups and there was a trend showing more patients of $\leq 5$ years of age and less patients of 10-15 years of age in the 2000-2013 group. We previously reported that younger children $(\leq 6$ years of age) might have a milder clinical course than older children ( $\geq 8$ years of age), assessed by weight change during hospitalization ${ }^{16)}$. Other studies have also indicated this trend in GAS infection ${ }^{1,2)}$ and APSGN $^{12)}$. The progressive decline in the incidence and severity of clinical findings of APSGN suggests that the pathogen-host relationship may change over time. Usually, some patients become carriers after GAS infection, and there are many GAS carriers among healthy children in various populations ${ }^{17-19)}$. In the mucosal immune system, the host-normal flora relationship is believed to be reciprocally beneficial, and normal flora rarely cause a disease when they invade into the host ${ }^{20)}$. A similar association may apply to the carrier-pathogen relationship after an infection. Recently, a study group showed that GAS strains in carriers contained a frameshift mutation which is involved in capsular production, and suggested that bacterial pathogens may downregulate or ablate the genes of virulence factors for the carriage strains in the host ${ }^{21)}$. Thus, from an evolutional perspective, it is possible that bacterial pathogens having tried to become normal flora within the human host, and GAS subtypes and human herd immunity may evolve to adapt to each other, just as other pathogens and the host do.

Patients admitted during 1987-1999 showed initial lower ASO values and lower C3. The ASO titer may have been influenced by the testing method as previously mentioned. The pathogenesis of APSGN, including low C3 level in the acute stage, remain to be further elucidated ${ }^{8,22)}$. Although elevated IgG and depressed C3 are noted in APSGN patients, serum IgG and C3 levels were not related to the clinical severity of the disease in the acute stage ${ }^{23,24)}$, and many patients have no IgG deposits except C3 in renal lesions ${ }^{24,25)}$. We previously found that the levels of IgG and ASO titer did not change, but C3 and IgM levels increased in the early convalescent stage of APSGN ${ }^{16)}$. Although APSGN is an acute-onset disease, few patients have fever and neutrophils are predominantly observed in the early glomerular lesions. These findings suggest that the innate immune system such as complement system and neutrophils of the host plays an important role for recovery during early stages of the disease.

There are some limitations in this retrospective study. APSGN patients in this series might be underestimated, because of our patient selection policy of C3 and ASO. Since this study was performed in a single hospital, our data might not be representative for the true epidemiological pattern of APSGN in Korea.

\section{Conclusion}

Our study suggests that APSGN has become a rare disease with a trend towards a weakened clinical course in Korea. This finding suggests that the prevalence of infection-related immune-mediated diseases can change over-time, along with both the changes of socioeconomic environment and changes in the pathogen-host relationship.

\section{Competing interests}

The authors declare that they have no competing interests.

\section{Acknowledgements}

This study has no fund. The authors thank Drs. SeongWoo Lee, Young-Hoon Song, Hyo-Jin Kim, and Sun-Mee Choi for help in data collection during study period. 


\section{References}

1. Markowitz M. Changing epidemiology of Group A streptococcal infections. Pediatr Infect Dis J 1994;13:557-60.

2. Quinn RW. Comprehensive review of morbidity and mortality trends for rheumatic fever, streptococcal disease, and scarlet fever: the decline of rheumatic fever. Clin Infect Dis 1989;11:928-53.

3. Simon P, Ramee MP, Autuly V, Laruelle E, Charasse C, Cam G, et al.Epidemiology of primary glomerular diseases in a French region: Variations according to period and age. Kidney Int 1994; 46:1192-8.

4. Coppo R, Gianoglio B, Porcellini MG, Maringhini S. Frequency of renal diseases and clinical indications for renal biopsies in children: Report of the Italian National registry of Renal Biopsies in Children. Nephrol Dial Transplant 1998;13:293-7.

5. Berrios X, Lagomarsino E, Solar E, Sandoval G, Guzman B, Riedel I. Poststreptococcal acute glomerulonephritis in Chile; 20 years of experience. Pediatr Nephrol 2004;19:306-12.

6. Wong W, Lennon DR, Crone S, Neutze JM, Reed PW. Prospective population-based study on the burden of disease from post-streptococcal glomerulonephritis of hospitalised children in New Zealand: epidemiology, clinical features and complications. J Paediatr Child Health 2013;49:850-5.

7. Rodriguez-Iturbe B, Musser JM. The current state of poststreptococcal glomerulonephritis. J Am Soc Nephrol 2008;19:1855-64.

8. Nitsche-Schmitz DP, Chhatwal GS. Host-pathogen interactions in streptococcal immune sequelae. Curr Top Microbiol Immunol 2013;368:155-71.

9. Song YK, Kim CK, Lee YI. Statistical studies on acute glomerulonephritis in children. J Korean Pediatr Soc 1969;12:423-30.

10. Bai SK, Cheun SJ, Kim PK, Yun DJ. Clinical follow-up studies on acute glomerulonephritis 220 cases. J Korean Pediatr Soc 1973; 16:305-13.

11. Koo SE, Hahn HW, Park YS. A clinical study of acute poststreptococcal glomerulonephritis in children, from 1994 to 2003. Korean J Pediatr 2005:48:606-13.

12. Yu R, Park SJ, Shin JI, Kim KH. Clinical patterns of acute poststreptococcal glomerulonephritis: a single center's experience. J Korean Soc Pediatr Nephrol 2011;15:49-57.

13. Kang HH, Cha SH, Lee KS, Lee SB, Kwon TC, Tockgo YC, et al. Clinical trends in acute rheumatic fever in Korean children: mailed questionnaire survey from 1988 to 1997(Compared with 1978-
1987). J Korean Pediatr Soc 1999:42:1381-91.

14. Zhang Y, Shen Y, Feld LG, Stapleton FB. Changing pattern of glomerular disease in Beijing Children's Hospital. Clin Pediatr 1994;33:542-7.

15. Roy S, Stapleton FB. Changing perspectives in children hospitalized with poststreptococcal acute glomerulonephritis. Pediatr Nephrol 1990;4: 585-8.

16. Kim DH, Lee SW, Lee KY, Youn YS, Hwang JY, Rhim JW, et al. The change of immunologic parameters in acute poststreptococcal glomerulonephritis. J Korean Soc Pediatr Nephrol 2009;13:13845.

17. Kaplan EL, Top FH Jr, Dudding BA, Wannamaker LW. Diagnosis of streptococcal pharyngitis: differentiation of active infection from the carrier state in the symptomatic child. J Infect Dis 1971;123:490-501.

18. Tanz RR, Shulman ST. Chronic pharyngeal carriage of group A streptococci. Pediatr Infect Dis J 2007;26:175-6.

19. Roberts AL, Connolly KL, Kirse DJ, Evans AK, Poehling KA, Peters $T R$, et al. Detection of group A streptococcus in tonsils from pediatric patients reveals high rate of asymptomatic streptococcal carriage. BMC Pediatr 2012;12:3.

20. Maynard CL, Elson CO, Hatton RD, Weaver CT. Reciprocal interactions of the intestinal microbiota and immune system. Nature 2012;489:231-41.

21. Flores AR, Jewell BE, Olsen RJ, Shelburne SA 3rd, Fittipaldi N, Beres SB, et al. Asymptomatic carriage of group A streptococcus is associated with elimination of capsule production. Infect Immun 2014:82:3958-67.

22. Rodriguez-Iturbe B, Batsford S. Pathogenesis of poststreptococcal glomerulonephritis: a century after Clemens von Pirquet. Kidney Int 2007;71:1094-104.

23. Rodrigez-Iturbe B, Carr RI, Garcia R, Rabideau D, Rurio L, Mclntosh RM. Circulating immune complexes and serum immunoglobulins in acute poststreptococcal glomerulonephritis. Clin Nephrol 1980;13:1-4.

24. West CD, McAdams AJ. Serum and glomerular lgG in poststreptococcal glomerulonephritis are correlated. Pediatr Nephrol 1998; 12:392-6.

25. Fish AJ, Herdman RC, Michael AF, Pickering RJ, Good RA. Epidemic glomerulonephritis associated with type 49 streptococcal pyodema. II. Correlative study of light, immunofluorescent and electron microscopic findings. Am J Med 1970;48:28-39. 